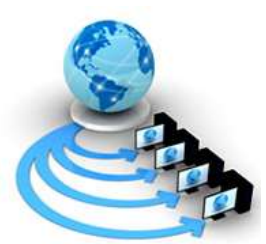

Volume 10, No. 1, January-February 2019

ISSN No. 0976-5697

International Journal of Advanced Research in Computer Science

RESEARCH PAPER

Available Online at www.ijarcs.info

\title{
UTILIZING SMS \& EMAIL NOTIFICATION: A HOMEOWNERS PAYMENT AND GUEST SERVICES IMPLEMENTING INTERNET OF EVERYTHING (IOE)
}

\author{
Carlo A. Batitis \\ College of Computer Studies \\ TrimexColleges, Biñan, Laguna, Philippines \\ Alily B. Delima \\ College of Computer Studies \\ TrimexColleges, Biñan, Laguna, Philippines
}

\author{
James Robert B. Ramos \\ College of Computer Studies \\ TrimexColleges, Biñan, Laguna, Philippines \\ Ronnel Joseph Yatco \\ College of Computer Studies \\ TrimexColleges, Biñan, Laguna, Philippines
}

\author{
Louie F. Agustin \\ College of Computer Studies \\ Trimex Colleges, Biñan, Laguna, Philippines
}

\begin{abstract}
UTILIZING SMS \& EMAIL NOTIFICATION: Homeowners Payment and Guest Services Implementing Internet of Everything (IOE) is a web- based system proposed to provide a big lift transforming most of the processes from manual to online. In a whole, the system will greatly impact the measures and operations of the subdivision. Unlike the manual payment system, this can take payment for homeowner's monthly dues and even subdivision's stickers which can generate ready-to-print receipt. For security matters, it prevents unauthorized guest entering the subdivision and monitor people coming and going within the subdivision's premise. As the highlight of the system, users varying on the level of access can utilize the system based on their scope and will even provide downloaded reports for client's maneuvers and analytics for reports and other matters. In totality, the function and features embedded within the system will transform all manual processes into a webbased system in a more convenient and safe way.
\end{abstract}

Keywords: Internet of Everything(IoE); RFID; SMS and Email Notification; Process management and payment; Information systems applications;

\section{INTRODUCTION}

In this study, we have observed that most of the subdivisions or villages here in the Philippines do not have a stable system that monitors the people entering the vicinity of the subdivision, thus, compromising the security of the subdivision and its residence.

Further, there are still subdivisions who are still using old clerical procedures regarding processing monthly dues and how they get and create a report out of the information they have been collected and stored. In today's time, procedures and process should be modernized. Hence, a system should be created that can store data for report generation which can be produced On Demand and can accept payment with receipt to ensure that payment procedures will be followed properly. Further, this should contain a function that can monitor guests coming and going within the subdivision.

In this way, clerical jobs will be more convenient which lessen human errors, and the monitoring function will add better security to the subdivision. Currently, South Fairway Homes Classic (SFHC) doesn't have an existing system for report generation for subdivision's operations, payment scheme, and guest monitoring. Thus, making the process difficult and flawed.

Our proposed system will suffice the needs of the subdivision turning the process into a more seamless way of managing reports, payment scheme, and guest monitoring.

\section{DESIGN OF THE STUDY}

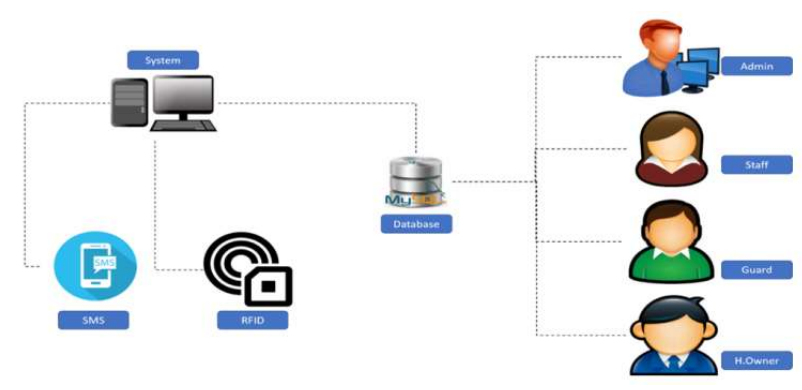

Figure1: System Architecture

The figure above illustrates the composition of the SFHC Guest Monitoring and Payment System. It has the 
Administrator who has an overall control on the system capable of generating all kinds of reports to the system's extent, manage guests, homeowners and can have an access of the status of the payment analytics report along with the real-time dashboard showing the count of guests per month, registered homeowners and transactions made. The Staff who make accepts payments and register homeowners, and Guard is the one responsible for monitoring the guests entering the subdivision's premise. IO and Process module are the ones handling the RFID and SMS for secured guest monitoring process. The Homeowners has access to request guest and view announcements.

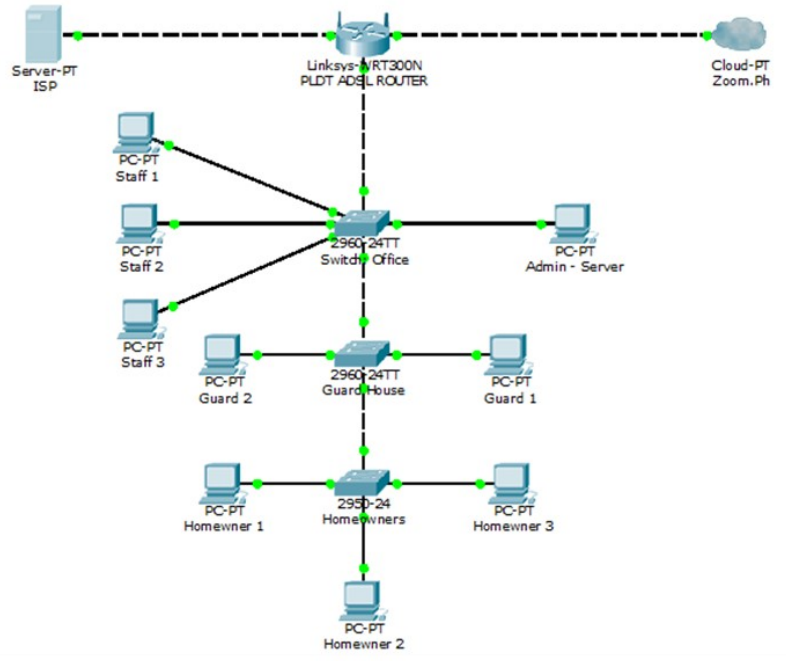

Figure 2: Network Design Infrastructure

The Figure above illustrates the network connectivity of each user depending on the purpose and objective. Each user has designated location as to where the objective will be done. Cloud storage of the third-party hosting company - Zoom PH - will be used to store data log by the users as this is where the system has been stored and running under the domain sfhc.gvsmanagement.com.

\section{DATABASE SCHEMA}

The figure below shows the database design of the proposed system. The database name is dbvillage and is consists of 11 tables followed by its fields.

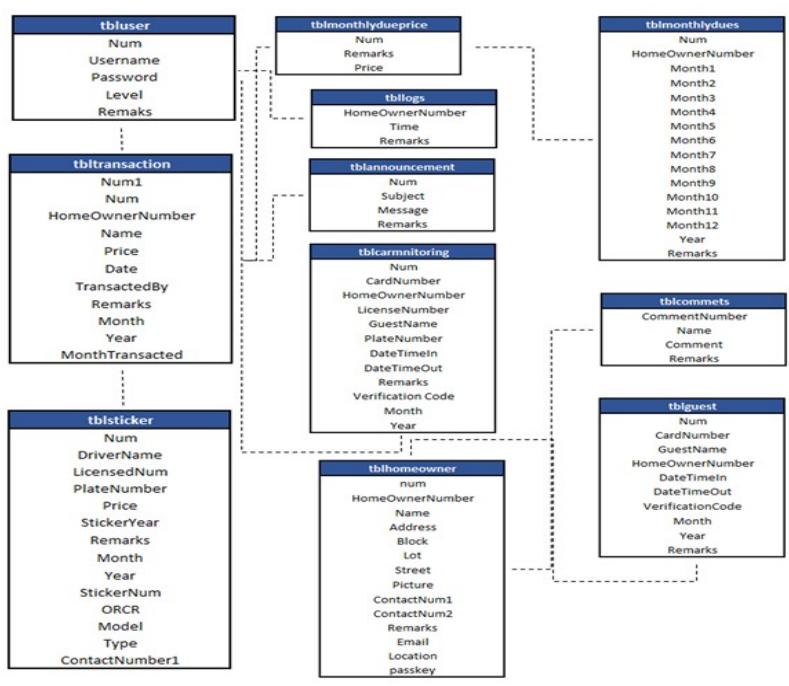

Figure 3: Database Schema

Figure 3 shows the database design of the proposed system. Iot defines how the data is organized and how the relation among them is associated. It formulates all the constraints that are to be applied to the data. It's database designers who designed the schema to help programmers understand the database and make it useful.

\section{LITERATURE SURVEY}

In this chapter, the researchers tackle the different concept, Understanding, Generalization, and guidance to achieve their target objectives by getting ideas on the related studies and make improvements.

\section{Guest Monitoring}

The people behind the "hoteliga" brand are the same people who started and continue with the original strong passion and commitment the development of the hoteliga cloud platform, for the management of the hotel and other accommodation properties, maintaining the company in a top position.

It was early 2014 when Dimitris and Eva came up with the idea about hoteliga. Their small office, a few meters away from Berlin's Alexanderplatz in Germany, turned into the origination of advancement and easy to use online framework for the administration of convenience properties.

Notwithstanding amid the mid-year of that year, some lodging properties worked with the PMS Programming of hoteliga. The entire advancement procedure of hoteliga from the plain first minute depended on genuine issues of hoteliers and settlement property proprietors, and this is something that made hoteliga emerge from the begin: Giving down to earth arrangements quickly and in close collaboration with the business specialists.

It is a part of the hoteliga philosophy to provide as many integrations with third parties as possible So that the customer-consumer can activate additional services freely and without limitation, with affordable costs or even without cost. In this context, hoteliga was officially integrated with 
the Italian channel manager RoomCloud (May 2016) and with the top-rated channel Manager Siteminder (May 2017), allowing accommodation properties access to hundred of sales channels around the world. In October 207 Aileron S.A.

\section{Short Message Service (SMS)}

A message is a form of communication it begins with language, the unique ability which has made possible the evolution of human society. With dialect, any message, regardless of how unpredictable, can be passed on to the general population over a constrained separation inside a room or a position of gathering, or over a short open space. The message peruses just inside perusing range; its beneficiaries must make a trip to get it. The framework is by and large progressively proficient on the off chance that it is the message which ventures. SMS stands for Short Message Service.

It is an innovation that empowers the sending and getting a message between cell phones. Adding content informing usefulness to cell phone started in the mid-1980s. The principal activity plan of the CEPT assemble GSM endorsed in December 1982; The SMS idea was created in the Franco-German GSM Collaboration in 1984 by FriedhelmHillebrand and Bernard Ghillebaert. Namrata A. Kale S.M. Karande (November 2014) International Journal of Advanced Reseach in Computer Science and Management Studies; Volume 2, Issue 11.

\section{RFID - Radio-Frequency Identification}

Distinguishing proof Everything began decades prior. As radars were created during the 1930s, military flying was first to send the innovation in bigger scale amid World War II. Backscattering radios were mainly utilized to identify friendly aircraft by modulating backscattered radar signal. Putting military technology aside, the first scientific landmark paper "Communication using Reflected Power" was presented a bit later by Harry Stockman in 1948. Initially, the innovation was utilized to screen cows that were taking drugs, yet the utilization before long extended.

A focal thought of the present development is having perceived that an effective idea for identifying radio recognizable proof transponders might be given when a receiving wire gadget includes computing implies designed to control feed signals for applying to a majority of reception apparatuses in a period differing way. The timevaryingly controlled feed signals allow obtaining a timevarying radiation pattern or characteristic of the antennas or the radio signal and a visual or reading range enlarged compared to static radiation patterns.

Chung (April 19, 2016) This investigation planned to efficiently survey all examinations that assessed the impacts of utilizing radio-recurrence distinguishing proof (RFID) for following patients in doctor's facilities. The PubMed and Embase databases were sought (to August 2015) for crucial English dialect contemplates, and those that assessed the impacts of an ongoing finding framework with RFID for patient following in doctor's facilities were recognized and removed the 652 examinations found, the 17 significant investigations were separated for consideration.

Five of the removed examinations utilized RFID frameworks in working theaters, two in crisis offices, one out of an attractive reverberation imaging office, one of every a radiology room, and the staying eight investigations were in different wards. In these investigations, highlights, for example, the achievability, exactness, accuracy, unwavering quality, security, dimension of fulfillment, cost of consideration, and time proficiency of the RFID frameworks were accounted for.

Of all the separated examinations, seven assessed the exactness of the frameworks in swarmed and unattended territories, and five of these were happy with their precision. Six assessed the dependability of the frameworks, and these observed the frameworks to be solid. Six assessed timereserve funds and every one of them revealed the frameworks to be time powerful.

\section{RESULTS AND DISCUSSION}

1. To monitor people entering the village and prevent unwanted guests.

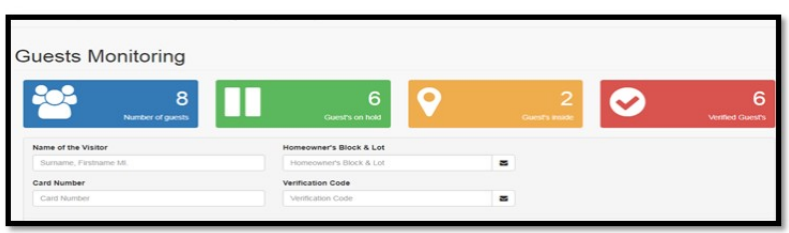

Figure 4: Guest Monitoring

The figure above will start the process of how the guest will be verified. The assigned guard will get the name of the visitor and confirmed the address of the homeowner

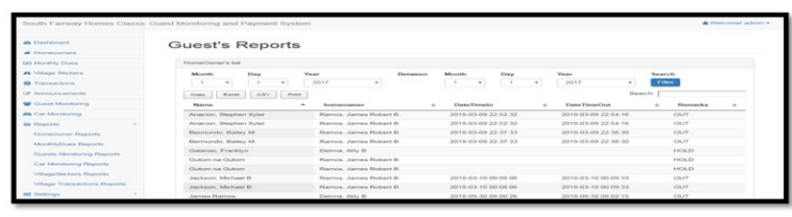

Figure 5: Guest Monitoring

The figure above shows the lists of the guests visited the subdivision. It will also provide timestamps and status of the visit.

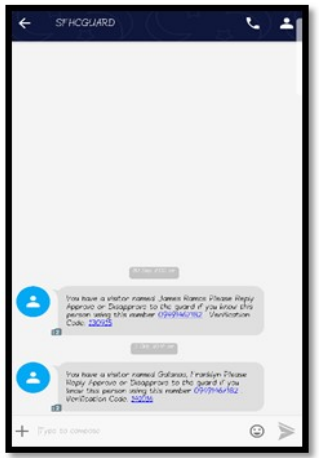

Figure 6: Guest Monitoring 
Once the information on Figure 1.2 is completed, the guard will send an SMS notification through the system with verification code confirming if the visitor will be accepted or not.

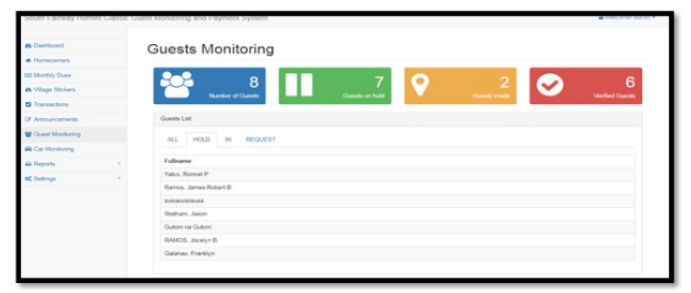

Figure 7: Guest Monitoring

The homeowner has to reply if they agree or not for the visitor to come in and confirmation will be received by the guard's service phone. If the Homeowner replies approve, then the visit will be given a queue number (101 is the queue number to the visitor).

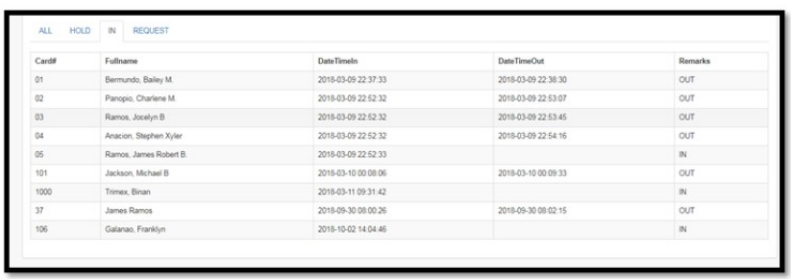

Figure 8: Guest Monitoring

Once the visitor is given a queue number, then status will change from HOLD to IN.

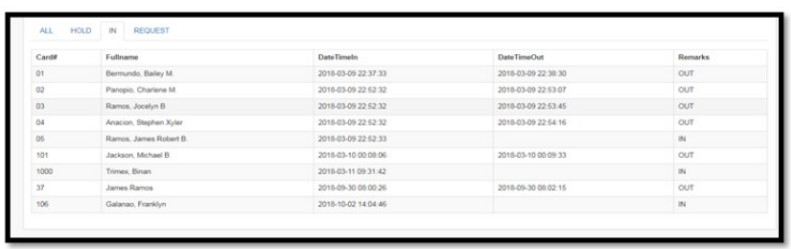

Figure 9: Guest Monitoring

2. To generate monthly and yearly reports for homeowner's transactions, Payments and other logs for subdivision's operations

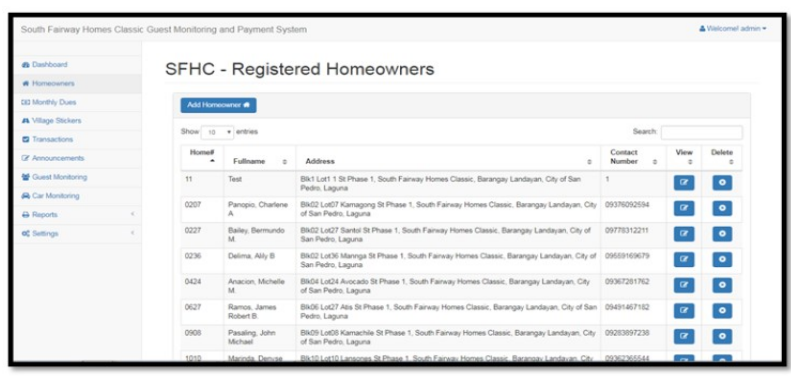

Figure 10: Reports - Homeowners Reports

The figure above shows the stored information regarding the registered homeowners of the SFHC. The user must choose and filter the file format that will be downloaded. On this snapshot, the admin will extract the details using excel format.

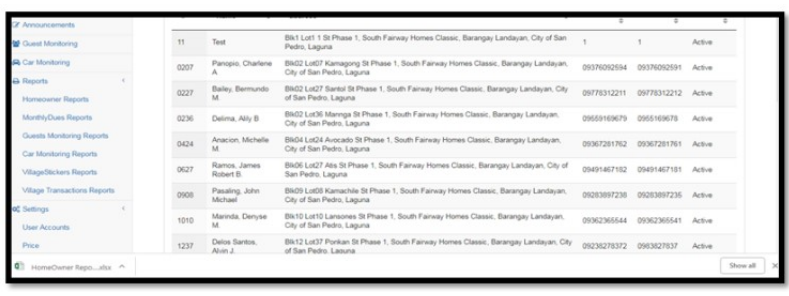

Figure 11: Reports - Homeowners Reports

The file will be downloaded on the same page after the user will choose the format of the file. The downloaded file will be stored on devices default download path.

3. To create a seamless way of letting the homeowners be aware of any upcoming events and an automated email notification that will serve as a reminder for monthly dues on every 15 th of the month.

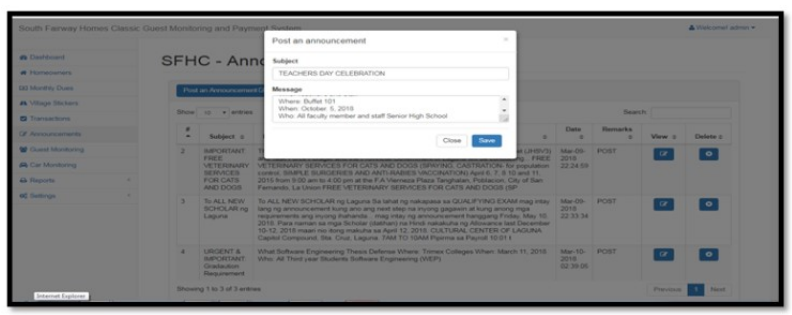

Figure 12: Announcement

The figure above allows the admin to post an important announcement and other information that must be relayed to the homeowners.

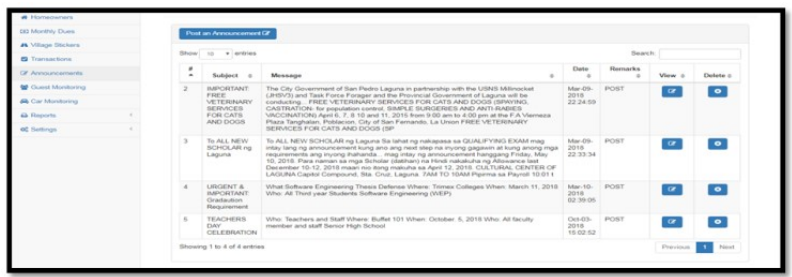

Figure 13: Announcement

The figure above shows that post made by the admin was saved under admin's access.

4. The admin will access the site using admin's authentication details. Default username and password will be an admin.

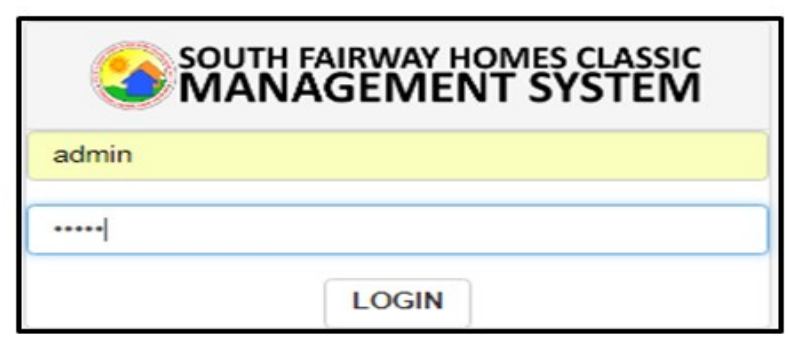

Figure 14: Admin Access 
The admin will access the site using admin's authentication details. Default username and password will be an admin.

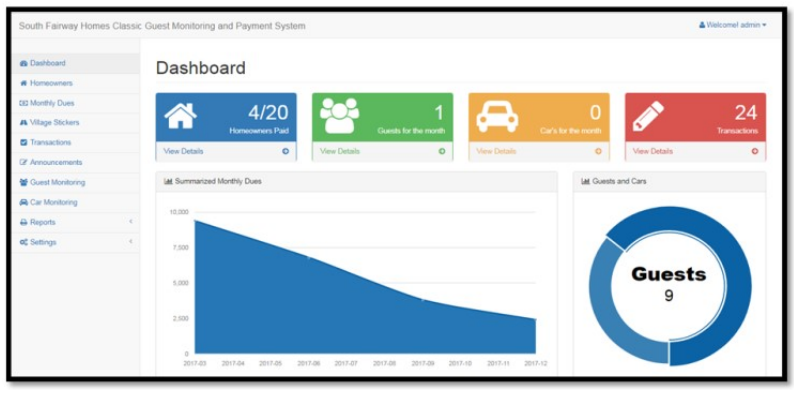

Figure 15 Admin Access

The figure above will show the first part of admin's access.

5. To provide a monthly overview of dues paid versus the target amount and summarized of payments made quarterly

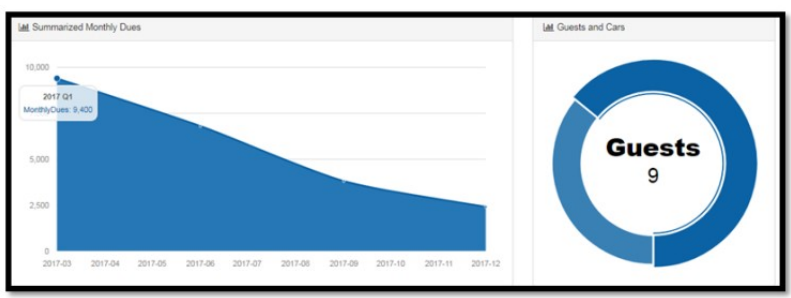

Figure 16: Monthly Payments

The figure above provides the running monthly dues paid quarterly. Legends at the left show the amount paid and legends at the bottom provides the year to month computation.

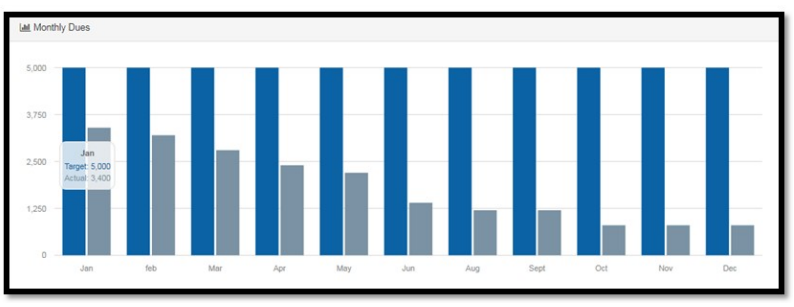

Figure 17: Monthly Payments
The figure above displays an overview of the actual paid amount versus the target collectibles per month.

\section{CONCLUSIONS}

1. To ensure the security of homeowners from an unwanted guest.

2. To ensure the management that the system can generate accurate monthly/yearly reports about payments and guest.

3. Our clients will have lesser man power services and cost-effective procedures in term of sending an announcement as they don't have to produce tarpaulins and go over the subdivision to deliver any announcement needed varying for its extent

4. Convenience in the system regarding usage can be observed as you will only get to see and use functions limited to your access

5. Clients will have easy access to the overview and dashboard at the same which can they check the running status and current numbers without manual calculations

6. After conducting the survey, the system resulted at $4.60-4.63$ resulting an Excellent regarding overall performance

\section{REFERENCES:}

[1] Dimitris van Leusden (2015),Meet the people behind hoteliga from

https://www.hoteliga.com/en/about

[2] Ray Jackendoff (2016) Linguistic Society of America from

https://www.linguisticsociety.org/resource/faq-how-didlanguage-begin

[3] JuhoPartanen, Co-founder of Voyantic Ltd. History of RFID from

https://rainrfid.org/wpcontent/uploads/2015/12/History-of-RFID.pdf. 